\title{
A PERDA GRAVE DO CAPITAL SOCIAL'
}

\author{
Paulo Alves de Sousa de Vasconcelos
}

\section{SUMÁRIO}

INTRODUÇÃO

1. NOÇÃO DE CAPITAL SOCIAL

2. FUNÇÕES DO CAPITAL SOCIAL

2.1. Nas relações internas

2.2. Nas relações externas

3. FONTES NORMATIVAS DO REGIME DA PERDA GRAVE

4. REGIME JURIDICO DA PERDA GRAVE

4.1. Noção de perda grave

4.2. Momento da verificação da perda grave

4.3. Obrigações a cargo dos gerentes e administradores

4.4. Publicidade da perda grave

4.5. Medidas a adoptar pelos sócios

5. CRISE DO CAPITAL SOCIAL

\section{INTRODUÇÃO}

Quem se inicia no estudo do direito das sociedades comerciais cedo se depara com o conceito de capital social. É um dos conceitos em que o nosso regime jurídico-societário assenta, encontrando-se presente ao longo de todo o Código das Sociedades Comerciais. Daí que, desde a sua estipulação no contrato, passando pelas regras relativas à

\footnotetext{
' Texto completo da lição apresentada no concurso de provas públicas para provimento de um lugar de professor coordenador, na área científica de Direito, do Instituto Superior de Contabilidade e Administração do Porto, em Julho de 2006.
} 
sua realização, conservação e alteração, o legislador se tenha preocupado em regular com especial cuidado o regime do capital social. E não só entre nós, pois pode afirmar-se que no direito societário europeu a noção de capital social tem uma importância decisiva, sendo-lhe até dedicada uma directiva da União Europeia, a Segunda Directiva sobre sociedades $^{2}$.

Este importantíssimo papel que o capital social desempenha pode levar-nos a pensar que estamos perante um elemento imprescindível ao regime societário, constituindo tal noção, por isso mesmo, uma pedra angular do sistema gizado pelo nosso legislador, sem o qual todo o edifício cairia.

Todavia, ao contrário dessa impressão que à primeira vista se pode colher, não se trata de um elemento imprescindível nem insubstituível. De resto, está hoje na ordem do dia a discussão acerca da sua continuidade, levando muitos a reflectir sobre se o capital social deverá permanecer como a tal pedra angular ou se, pelo contrário, não será preferível procurar melhor alternativa, face às limitações e inconvenientes que the podem ser apontados ${ }^{3}$.

Ora, um ponto crítico de todo o regime que rege o capital social é exactamente o referente à sua perda grave, isto é, sua perda relevante. Nele se reflectem as funções que o capital social é chamado a desempenhar e a importância que o legislador lhe atribui. Nele se revelam também as insuficiências do seu regime legal, que suscitam a tal dúvida quanto à continuidade do capital social como elemento central do regime societário europeu.

E este é um tema jurídico que interessa particularmente aos contabilistas e aos gestores de empresas, sendo certo que também os juristas terão de se servir de elementos que a contabilidade nos traz, como veremos.

\footnotetext{
${ }^{2}$ Directiva n. ${ }^{\circ} 77 / 91 /$ CEE, do Conselho, de 13/12/1976, JOCE n. ${ }^{\circ}$ L-26, 1-13, de 31 de Janeiro de 1977 (o texto consolidado está disponível em «http://europa.eu.int/eur-lex/ pt/consleg/main/1977/pt_1977LL0091_index.html»).

${ }^{3} \mathrm{Cf}$. a «Comunicação da Comissão ao Conselho e ao Parlamento Europeu-Modernizar o direito das sociedades e reforçar o governo das sociedades da União Europeia - Uma estratégia para o futuro», de 21 de Maio de 2003 (disponível em «http://europe.eu.int/ eur-lex/pt/com/cnc/2003/com2003_0284pt01.pdf»), em especial o ponto 3.2., em que se propõe o estudo de um regime alternativo ao capital social. Esta Comunicação foi elaborada na sequência do relatório do grupo de peritos, presidido por JAAP WINTER.
} 
Importa, então, analisar a perda grave do capital social. Para tal, começaremos por ver em que consiste o capital social.

\section{NOÇÃO DE CAPITAL SOCIAL}

Apesar da importância que a lei lhe confere, o nosso legislador não define capital social. Terá, pois, que ser o intérprete a construir tal noção.

Diga-se, antes de mais, que só por simplificação excessiva se poderá dizer que o capital social é a cifra correspondente à soma das entradas dos sócios. Um exemplo demonstra-o com evidência.

Admitamos que o António, o Bento e a Carla, finalistas do ISCAP, decidem constituir uma sociedade por quotas, a "ABC, Lda.", com o capital social de $€ 30000,00$, dividido em três quotas de igual valor nominal, para prestar serviços de contabilidade. Eles sabem que o capital pode ser realizado em dinheiro ou espécie, pelo que a Carla opta por dar de entrada o seu SMART, que um revisor oficial de contas independente avaliou em $€ 12000,00$. Ora, neste caso, fácil é concluir que o capital social não é igual à soma do valor das entradas, pois estas perfazem $€ 32000,00$ e aquele ascende a $€ 30000,00$.

O mesmo poderá suceder quando haja emissão de acções acima do par ou contribuições de indústria ${ }^{4}$. Assim, em todas estas hipóteses, deixa de ser verdade que o capital social "é a soma das entradas". Daí que seja preferível defini-lo como a «cifra representativa da soma dos valores nominais das participações sociais fundadas em entradas em dinheiro e/ou espécie" ${ }^{\text {. }}$. Valor que é fixado no pacto social e é tendencialmente estável ${ }^{6}$.

Trata-se, assim, de uma noção distinta da noção de património so-

\footnotetext{
${ }^{4}$ As contribuições de indústria não são computadas no capital social - $\operatorname{art.~} 178 .^{\circ}, \mathrm{n} .{ }^{\circ} 1$, do Código das Sociedades Comerciais (doravante CSC).

${ }^{5}$ Cf. Coutinho de Abreu, Curso de Direito Comercial, p. 66

${ }^{6}$ Esta pode ser, pelo menos, a definição de capital social correspondente à sua vertente formal, para quem entenda que o capital social se reveste de duas faces: uma formal, a tal cifra, e outra real, correspondente à «massa de bens - não determinada qualitativamente - que é uma fracção ideal do património liquido e se destina a cobrir o valor do capital social nominal, estando os sócios obrigados a conservar intacta tal quantidade de bens que apenas poderá ser afectada pelos azares e vicissitudes da actividade empresarial» - Cf. Paulo de TArso Domingues, Do Capital Social, p. 54.
} 
cial e com ela contrastante. De facto, o património é um valor real e, como tal, variável, enquanto o capital social é uma cifra, isto é, um número, um valor ideal, e portanto, constante.

No nosso exemplo, no momento da constituição da sociedade o património social era de $€ 32000,00$ e o capital social de $€ 30000,00$; mas, um mês volvido, depois de pagas as primeiras rendas do escritório que a sociedade arrendou, o património líquido já será menor que o inicial, como por regra sucede nos primeiros meses após o início da actividade social, permanecendo o capital social o mesmo.

No nosso sistema jurídico, esta cifra que é o capital social, desempenha importantes funções. Vejamos quais são essas funções.

\section{FUNÇÕES DO CAPITAL SOCIAL}

As múltiplas funções que o capital social desempenha podem ser divididas em dois grandes grupos, de acordo com o círculo de interesses que visa tutelar: as funções que desempenha nas relações internas ( $a d$ intra), isto é, entre os sócios, e as que é chamado a cumprir nas relações externas, face a terceiros (ad extra).

\subsection{Nas relações internas}

O capital social permite efectuar uma avaliação da situação económica da empresa. Isto é possível porque esta cifra é o ponto de referência que permite fazer a medição, por comparação com o valor do património líquido (ou situação líquida) ${ }^{7}$. De facto, possibilita a comparação do activo líquido em cada momento, com o valor que os sócios afectaram de forma permanente ao exercício da actividade social. Se aquele património líquido for de valor superior ao capital social é sinal de que há lucro, isto é, o activo fornecido pelos sócios foi incrementado pela actividade social. Se é menor, significa que a sociedade teve prejuízos.

\footnotetext{
${ }^{7}$ Nas palavras de PAULO DE TARso DomingueS, «O capital nominal - enquanto cifra fixa, constante do lado direito do balanço - é uma noção instrumental que serve para a determinação do lucro ou da existência de perdas e, de um modo geral, para a avalização da situação económica da empresà - PAUlo de TARso Domingues, Do Capital Social, p. 71. No mesmo sentido, Broseta Pont / Martinez Sanz, Manual de Derecho Mercantil, p. 341 .
} 
Voltando ao nosso exemplo. Se a sociedade, "ABC, Lda." após um ano de actividade, tiver um património líquido (ou capital próprio) no valor de $€ 40000,00$, podemos afirmar, por comparação com o valor do capital social, que a sociedade obteve ganhos, que o património inicial já sofreu um incremento. Se, ao invés, o mesmo se cifrasse em $€ 20000,00$, seria sinal de que a sociedade teve perdas.

$\mathrm{O}$ apuramento dos lucros e perdas da sociedade efectua-se, deste modo, por referência ao capital social.

O capital social tem, também, a função de determinação dos direitos e obrigações dos sócios. É o que sucede, por exemplo, com o direito ao lucro ${ }^{8}$, com o direito de voto 9 e com o direito à informação ${ }^{10}$.

Assim, no momento de votar em assembleia geral ${ }^{11}$ ou de proceder à distribuição de lucros, o critério é o do capital social que cada sócio subscreveu. No nosso caso, todos têm os mesmos votos e todos têm direito à mesma fracção dos lucros, pois todos participam em igual proporção no capital social ${ }^{12}$.

Do mesmo modo, a aferição da validade de certas deliberações dos sócios, o quórum das assembleias gerais e as maiorias necessárias, são determinados por referência ao capital social.

Por último, é o capital social que proporciona a formação da estrutura de produção, isto é, dota a sociedade do seu património inicial, base da sua actividade social. É a chamada função de produção.

Também por essa razão, não é exacto afirmar que o capital social é «a cifra representativa da soma entradas dos sócios» ${ }^{13}$. É que, na maior parte das situações, o valor de que se parte, em função das necessidades de financiamento da sociedade, é o valor do capital social. Pelo que, é este que determina o valor das entradas dos sócios e não o contrário ${ }^{14}$.

$\mathrm{Na}$ nossa hipótese, os três sócios terão fixado o capital social em $€ 30000,00$ de acordo com as previsões que fizeram quanto às neces-

\footnotetext{
${ }^{8} \mathrm{Cf}$. art. $22{ }^{\circ}$ do CSC.

${ }^{9} \mathrm{Cf}$. art. $250{ }^{\circ}$ e $384 .^{\circ}$, do CSC.

${ }^{10} \mathrm{Cf}$. art. $291 .^{\circ}$ do CSC

${ }^{11} \mathrm{Cf}$. art. $383{ }^{\circ}$ do CSC.

${ }^{12} \mathrm{Cf}$., por exemplo, artigos $217 .^{\circ}$ e $265 .^{\circ}$ do CSC.

${ }^{13}$ Cf., por exemplo, Ferrer Correia, Lições de Direito Comercial, p. 218.

${ }^{14} \mathrm{Ou}$, como afirma Paulo de Tarso Domingues, Do Capital Social, p. 43, «são as entradas que se definem em função do capital social».
} 
sidades de financiamento da sociedade, face à actividade que se propuseram realizar. E é lógico que, encontrando esse valor, tenham depois decidido a forma mais adequada da sua distribuição, atentas as disponibilidades de cada um e os equilíbrios de poder que da distribuição do capital resultam.

\subsection{Nas relações externas}

Se o capital social é um elemento importante na organização interna da sociedade e na repartição do poder societário entre os sócios, é nas relações com terceiros, maxime, com os credores da sociedade, que ele desempenha a sua principal função ${ }^{15}$. É a função de garantia.

Assim, podemos dizer que para os credores da sociedade o capital social é uma garantia, o que decorre essencialmente dos princípios da intangibilidade e da efectividade a que está sujeito o capital social ${ }^{16}$.

$\mathrm{O}$ que se quer significar quando se diz que o capital social é uma garantia para os credores da sociedade? Como sabemos, nas sociedades de responsabilidade limitada (sociedades por quotas e sociedades anónimas, que em conjunto constituem a esmagadora maioria das sociedades existentes em Portugal), os sócios não são responsáveis pelas dívidas da sociedade, pelo que os credores só poderão ver satisfeitos os seus créditos à custa do património social. Em bom rigor, a garantia que os credores têm é o património da sociedade, pois a garantia do credor é o património do devedor. Por que razão se afirma então que o capital social é uma garantia para os credores?

Fundamentalmente pela razão de que o capital social funciona como uma "cifra de retenção", isto é, como uma barreira, um dique que impede que o património social desapareça, com ele desaparecendo toda a garantia dos credores.

Tal desiderato é obtido, desde logo, através diversas regras previstas no CSC, das quais se destacam:

- A proibição de distribuição de bens aos sócios. Não podem ser distribuídos bens aos sócios quando a situação líquida da sociedade for

\footnotetext{
${ }^{15}$ A função de garantia é «de longe considerada, na literatura jurídica, como a função rainha do capital social» - Paulo de Tarso Domingues, Do Capital Social, p. 200.

${ }^{16}$ Essencialmente, pois também o princípio da exacta formação contribui para tal - cf. Paulo de Tarso Domingues, Do Capital Social, p. 200.
} 
inferior à soma do capital social e das reservas indisponíveis, ou se tornasse inferior em consequência dessa distribuição ${ }^{17}$. O que significa que só é permitida a distribuição de lucros.

- A proibição da retribuição certa, a título de juros ou de lucros ${ }^{18}$. Isto é, como a actividade societária é por natureza aleatória, sujeita ao risco, um cláusula que assegurasse uma retribuição certa colidiria com a proibição de restituição das entradas, como é fácil de constatar.

- A imodificabilidade do capital social. Tal não quer dizer que o capital social não possa, de todo em todo, ser alterado. Significa que a sua alteração é sempre um acto extraordinário na vida societária e que exige a verificação de especiais requisitos, implicando uma alteração do pacto, registo na respectiva conservatória e, eventualmente, uma autorização judicial (no caso da redução do capital exuberante).

Compreende-se a importância destas regras para a protecção dos interesses dos credores. Todavia, mesmo a sua actuação conjunta não assegura que a sociedade tenha património, ou pelo menos que tenha um património líquido equivalente, no mínimo, ao valor do seu capital social. Com estas regras apenas se garante, e não é coisa pouca, que o património social não desaparece em favor dos sócios. Isto é, assegura a todos os credores que os sócios não podem retirar da sociedade as entradas que efectuaram. Mas não evita que o património se possa reduzir a valores inferiores ao capital social, por efeito de uma actividade social deficitária.

Nada garante que algum tempo após a constituição da sociedade "ABC, Lda." o seu património líquido seja igual ou superior ao capital social. O que as regras do capital social nos asseguram é que, face a eventuais dificuldades da sociedade que levem a que o património seja inferior ao capital social, os três sócios não podem deliberar distribuir por eles próprios o activo restante, recuperando deste modo parte das entradas realizadas.

$\mathrm{Na}$ verdade, as contribuições que os sócios efectuam a título de entrada para a sociedade não ficam guardadas num cofre, afastadas dos perigos de erosão decorrentes da actividade social. Pelo contrário, podem, desde o primeiro momento, ser usadas para a persecução do ob-

\footnotetext{
${ }^{17}$ Como está consagrado no art. $32 .^{\circ}$ do $\operatorname{CSC}$ e no $15 .^{\circ}, \mathrm{n} .^{\circ} 1$, a) da Segunda Directiva sobre sociedades.

${ }^{18} \mathrm{Cf}$. art. $21^{\circ},{ }^{\circ}$ n. ${ }^{\circ} 2$, do CSC.
} 
jecto social. A maior garantia seria a que assegurasse que o património social nunca seria de valor inferior ao capital social. Ou seja, tratar-se-ia de obrigar a sociedade a manter sempre uma certa proporção entre o património e o capital social.

Na nossa hipótese, tratar-se-ia de saber se a sociedade pode continuar a exercer a sua actividade com um capital social de $€ 30000,00$, quando porventura o seu património líquido se reduzir a $€ 10000,00$.

É esse desiderato que tem sido apontado ao chamado regime da perda grave, procurando dessa forma dar efectiva consistência à ideia de que o capital social é uma garantia para terceiros, pois estes sabem que qualquer sociedade deverá ter um património líquido no mínimo correspondente a uma parte (metade, no nosso caso) do seu capital social $^{19}$

É o que vamos ver a seguir.

\section{FONTES NORMATIVAS DO REGIME DA PERDA GRAVE}

A perda grave do capital social está prevista, essencialmente, no art. $35 .^{\circ}$ do $\mathrm{CSC}^{20}$. Esta norma visa efectuar a transposição para o ordenamento jurídico português do previsto no art. $17 .^{\circ}$ da Segunda Directiva da União Europeia sobre sociedades, que no seu n. ${ }^{\circ} 1$, estabelece o seguinte:

«No caso de perda grave do capital subscrito, deve ser convocada uma assembleia geral no prazo fixado pelas legislações dos Estados-membros, para examinar se a sociedade deve ser dissolvida ou se deve ser adoptada qualquer outra medida.»

Acrescenta o n. ${ }^{\circ} 2$ da mesma norma que,

«Para os efeitos do previsto no n. ${ }^{\circ} 1$, a legislação de um Estado-membro não pode fixar em mais de metade do capital subscrito o montante da perda considerada grave.»

A razão de ser desta norma é, assim, a de proteger as expectativas de terceiros que confiaram na existência de um património social próximo do valor do capital social, evitando que de perda em perda se chegue

\footnotetext{
${ }^{19} \mathrm{O}$ valor do capital social de cada sociedade é um dado público, como é exigido pela Segunda Directiva sobre sociedades no seu art. $3^{\circ}$.

${ }^{20}$ Sobre os antecedentes do regime da perda grave, em Portugal e no estrangeiro, ver Menezes Cordeiro, "A perda de metade do capital social e a reforma de 2005: um repto ao legislador", p. 55 e ss.
} 
à perda total sem que nenhum aviso seja dado aos sócios. Desta forma, o que a norma em análise impõe verdadeiramente é que, perdida parte substancial do capital social, se faça soar um sinal de alarme dirigido em primeira mão aos sócios ${ }^{21}$.

Assim, perante a perda de metade do capital social, os sócios devem analisar a situação e adoptar medidas tendentes a remediá-la, dissolvendo a sociedade ou adoptando medidas de saneamento.

A ideia seria a de obrigar todas as sociedades anónimas ${ }^{22}$ a manter uma certa proporção de cobertura do capital social: o capital próprio (ou situação líquida) não deve ser inferior a metade do capital social. Todavia, esta norma não vai ao ponto de impor a obrigatoriedade de manutenção de um rácio de cobertura do capital social.

Poderá, então, dizer-se que o regime da perda grave reforça a ideia de que o capital social é uma garantia, embora indirecta, na medida em que visa assegurar a existência de um património social com um valor que não se afaste significativamente do valor do capital social, o qual funciona assim como um valor de referência.

Em Portugal, como já se disse, o regime da perda grave do capital social, está vertido no artigo $35 .^{\circ}$ do Código das Sociedades Comerciais.

Sucede que, tendo o CSC entrado em vigor em 1986, o certo é que este artigo $35 .^{\circ}$ apenas começou a fazer parte do direito vigente em Setembro de $2001^{23}$, após um período de 15 anos durante os quais permaneceu "suspenso". Isto é, existia como norma do CSC mas não era aplicável, pois não estava em vigor no ordenamento jurídico português ${ }^{24}$.

\footnotetext{
${ }^{21}$ Parece, pois, corresponder mais ao modelo informativo, de inspiração germânica, que contrasta com o regime francês, de modelo reactivo.

${ }^{22}$ A Segunda Directiva sobre sociedades tem por objecto apenas as sociedades anónimas (art. $1^{\circ}{ }^{\circ}$ ). Porém, em Portugal o regime da perda grave está regulado na parte geral do CSC, pelo que é aplicável a todos os tipos de sociedades comerciais. É uma solução muito discutível, sobretudo em relação às sociedades de responsabilidade ilimitada, as quais podem nem ter capital social.

${ }^{23}$ Pelo DL n. ${ }^{\circ}$ 237/2001, de 30 de Agosto.

${ }^{24} \mathrm{Na}$ verdade, o DL n. ${ }^{\circ} 262 / 86$, de 2 de Setembro, que aprovou o Código das Sociedades Comerciais, estabelecia no seu artigo $2 .^{\circ}$ que o código entrava em vigor em 1 de Novembro de 1986 , mas com a ressalva do artigo $35^{\circ}$, cuja entrada em vigor seria fixada em diploma legal posterior. Tal diploma apenas surgiria em Agosto de 2001. Só a partir de então o art. $35 .^{\circ}$ entrou em vigor.
} 
Refira-se, no entanto, que para as sociedades anónimas sempre esteve em vigor o artigo $544 .^{\circ}$ do CSC, que dispunha que seus os credores podiam requerer a dissolução societária «provando que, posteriormente à época dos seus contratos, metade do capital social» estava perdido. Esta norma destinava-se a funcionar enquanto o artigo $35 .^{\circ}$ não entrasse em vigor.

Tendo entrado em vigor em 2001 , a sua redacção original ${ }^{25}$ não resistiu muito tempo.

De facto, poucos meses depois, a sua redacção foi alterada, agora pelo DL n. ${ }^{\circ} 162 / 2002$, de 11 de Julho ${ }^{26}$.

Como se adivinhava, no exacto momento em que a sua aplicação passaria a ter efeitos na prática o artigo $35 .^{\circ}$ foi de novo alterado, agora

\footnotetext{
${ }^{25} \mathrm{Na}$ sua redacção original o artigo $35 .^{\circ}$ estipulava o seguinte: «Artigo $35 .^{\circ}$

Perda de metade do capital
}

1. Os membros da administração que, pelas contas do exercício, verifiquem estar perdida metade do capital social devem propor aos sócios que a sociedade seja dissolvida ou o capital seja reduzido, a não ser que os sócios se comprometam a efectuar e efectuem, nos 60 dias seguintes à deliberação que da proposta resulta, entradas que mantenham pelo menos em dois terços a cobertura do capital.

2. A proposta deve ser apresentada na própria assembleia que apreciar as contas ou em assembleia convocada para os 60 dias seguintes àquela ou à aprovação judicial, nos casos previstos pelo artigo 67. .

3. Não tendo os membros da administração cumprido o disposto nos números anteriores ou não tendo sido tomadas as deliberações ali previstas, pode qualquer sócio ou credor requerer a tribunal, enquanto aquela situação se mantiver, a dissolução da sociedade, sem prejuizo de os sócios poderem efectuar as entradas referidas no $n .^{\circ} 1$ até ao trânsito em julgado da sentença.»

Nos termos desta norma, uma obrigação se impunha aos gerentes e administradores: ao verificarem pelas contas do exercício, que a situação líquida (ou o capital próprio) era inferior a metade do capital social, deveriam alertar os sócios de tal facto (nomeadamente referindo-o no relatório de gestão), propondo-lhes a dissolução da sociedade, a redução do capital ou a reintegração das entradas perdidas. Caso isto não fosse efectuado, ou caso não viessem a ser tomadas medidas capazes de repor a cobertura do capital em pelo menos dois terços, a consequência era a possibilidade de qualquer credor poder requerer judicialmente a dissolução da sociedade. Em todo o caso, até ao trânsito em julgado da sentença era ainda possível remediar a situação, repondo o equilíbrio entre o capital social e a situação líquida.

${ }^{26}$ Com a publicação do DL n. ${ }^{\circ} 162 / 2002$, que alterou também o art. $141 .^{\circ}$ do CSC, a redacção do artigo $35^{\circ}$ passou a ser a seguinte: 
pelo DL n. ${ }^{\circ} 19 / 2005$, de 18 de Janeiro ${ }^{27}$ (que alterou também os arti-

«Artigo 35."

Perda de metade do capital

1. Os membros da administração que, pelas contas do exercicio, verifiquem estar perdida metade do capital social devem mencionar expressamente tal facto no relatório de gestão e propor aos sócios uma ou mais das seguintes medidas:

A dissolução da sociedade;

A redução do capital social;

A realização de entradas em dinheiro que mantenham pelo menos em dois terços a cobertura do capital social;

A adopção de medidas concretas tendentes a manter pelo menos em dois terços a cobertura do capital social.

2. Considera-se estar perdida metade do capital social quando o capital próprio constante do balanço do exercicio for inferior a metade do capital social.

3. Os membros da administração devem apresentar a proposta prevista no $n .^{\circ} 1$ na assembleia geral que apreciar as contas do exercício, ou em assembleia convocada para os 90 dias seguintes à data do início da assembleia, ou à aprovação judicial, nos casos previstos no artigo $67 .^{\circ}$.

4. Mantendo-se a situação de perda de metade do capital social no final do exercicio seguinte àquele a que se refere o $n^{\circ}{ }^{\circ} 1$, considera-se a sociedade imediatamente dissolvida, desde a aprovação das contas daquele exercício, assumindo os administradores, a partir desse momento, as competências de liquidatários, nos termos do artigo $151 .^{\circ}$. . Importa sublinhar que o artigo $35^{\circ} .^{\circ}$ continuou a dirigir-se em primeira mão aos gerentes e administradores, impondo-lhes as obrigações de mencionarem a perda de metade do capital social no relatório de gestão e de proporem aos sócios a adopção de medidas tendentes a alterar tal situação, passando a assumir a competência de liquidatários, caso persistisse a situação de perda grave. A obrigação de proporem aos sócios uma solução deveria ser cumprida na própria assembleia geral que apreciasse as contas do exercício ou em assembleia convocada para os 90 dias seguintes, e as propostas a apresentar aos sócios poderiam ser a dissolução da sociedade, a redução do capital social, a realização de entradas em dinheiro ou a adopção de quaisquer outras medidas que assegurassem a cobertura do capital em pelo menos dois terços. Caso a situação de perda grave se mantivesse pelo segundo ano consecutivo, a consequência seria a dissolução imediata no final do exercício seguinte àquele a que se referia o $n .{ }^{\circ} 1$ do artigo $35 .^{\circ}$. Por virtude do disposto no n. $^{\circ} 2$ do artigo $2 .^{\circ}$ do referido DL n, ${ }^{\circ} 162 / 2002$, o exercício de 2003 seria o primeiro exercício relevante para a aplicação do disposto no $\mathrm{n}^{\circ} 4$ do artigo $35^{\circ}$. Isto é, a contagem para efeitos de dissolução imediata só começava a contar no exercício de 2003. Desta forma, a dissolução automática apenas poderia ocorrer em 2005, com a aprovação das contas do exercício de 2004. Assim, se pelas contas do exercício de 2003 o capital próprio fosse inferior a metade do capital social e se a mesma situação se verificasse nas contas do exercício de 2004 , com a aprovação destas considerar-se-ia a sociedade imediatamente dissolvida.

${ }^{27}$ Com efeitos desde 31 de Dezembro de 2004. 
gos $\left.141 .^{\circ} \mathrm{e} 171 .^{\circ}\right)$. O objectivo da nova alteração foi a de pôr termo à sanção de dissolução automática das sociedades que a última versão do preceito legal determinava, que nem a própria Directiva impunha, ou sequer sugeria.

Agora, nos termos desta redacção, a consequência decorrente da perda de metade do capital social passa a ser tão-só a obrigação da administração promover a convocação de uma assembleia geral, para nela os sócios serem informados da perda grave, e a obrigação de publicitação de tal situação, como veremos a seguir.

Por fim, o n. ${ }^{\circ} 1$ deste artigo foi uma vez mais alterado, na reforma do direito societário introduzida pelo DL n. ${ }^{\circ} 76-\mathrm{A} / 2006$, de 29 de Mar$c \mathrm{C}^{28}$, para adequar a sua redacção à nova designação dos órgãos sociais do modelo germânico das sociedades anónimas, eliminando a referência aos «directores». Mas o regime é substancialmente o mesmo.

$\mathrm{O}$ referido artigo $35 .^{\circ}$ tem hoje a seguinte redacção ${ }^{29}$ :

«Artigo 35.

Perda de metade do capital

1 - Resultando das contas de exercício ou de contas intercalares, tal como elaboradas pelo órgão de administração, que metade do capital social se encontra perdido, ou havendo em qualquer momento fundadas razões para admitir que essa perda se verifica, devem os gerentes convocar de imediato a assembleia geral ou os administradores requerer prontamente a convocação da mesma, a fim de nela se informar os sócios da situação e de estes tomarem as medias julgadas convenientes.

2 - Considera-se estar perdida metade do capital social quando o capital próprio da sociedade for igual ou inferior a metade do capital social.

3 - Do aviso convocatório da assembleia geral constarão, pelo menos, os seguintes assuntos para deliberação dos sócios:

A dissolução da sociedade;

A redução do capital social para montante não inferior ao capital próprio da sociedade, com respeito, se for caso disso, do disposto no n. ${ }^{\circ} 1$ do artigo $96^{\circ}$;

\footnotetext{
${ }^{28}$ Que entra em vigor, nesta parte, no dia 30 de Junho de 2006.

${ }^{29}$ Redacção cujo n. ${ }^{\circ} 1$ é muito semelhante ao art. 92, 1, da AktG (Lei alemã sobre sociedades anónimas e em comandita por acções, de 6 de Setembro de 1965).
} 
A realização pelos sócios de entradas para reforço da cobertura do capital.»

Passemos então à análise das principais notas do regime actualmente em vigor.

\section{REGIME JURÍDICO DA PERDA GRAVE}

\subsection{Noção de perda grave}

A constatação da perda grave há-de resultar do confronto entre dois valores constantes das contas da sociedade comercial: o capital social e o capital próprio. Trata-se, na verdade, de dois valores essenciais e distintos na sua natureza. O capital social, como vimos, é uma cifra que consta do pacto social, pelo que é um número invariável (nos termos em que vimos). Representa o valor nominal das entradas dos sócios, em dinheiro e em espécie, já realizadas ou a realizar. No outro termo da comparação temos o capital próprio, valor contabilístico constante do lado direito do balanço ${ }^{30}$, e que é por natureza um valor variável, pois exprime um valor patrimonial em permanente alteração. O capital próprio é o valor que resulta do confronto entre os valores do activo e do passivo, exprimindo desta forma, o que resta se ao activo subtrairmos o passivo.

De acordo com o art. $35 .^{\circ}$ do CSC, estaremos perante uma perda grave do capital social quando o capital próprio (isto é, o activo descontado do passivo) for igual ou inferior a metade da cifra do capital social (subscrito, esteja ou não realizado). Ora, se o património líquido da sociedade apenas cobre metade (ou menos de metade) do capital social, significa que a sociedade, no exercício da sua actividade, teve prejuízos que consumiram pelo menos metade do património que os sócios afectaram à actividade que exercem em comum. Pode, então, dizer-se que

\footnotetext{
${ }^{30} \mathrm{O}$ capital próprio, de acordo com o POC, é composto pelo capital social, acções e quotas próprias, prestações suplementares, prémios de emissão de acções, ajustamentos de partes de capital em filiais e associadas, reservas de várias espécies, subsídios, doações, resultados transitados, resultado líquido do exercício e dividendos antecipados.
} 
a perda é grave ${ }^{31}, 32$

Dir-se-á que a nossa "ABC, Lda." teve uma perda grave do seu capital se as suas contas do exercício de 2005 apresentarem um capital próprio, por hipótese, de $€ 10000,00$.

\subsection{Momento da verificação da perda grave}

O momento relevante para aferir da existência da perda é, em primeiro lugar, quando se elaboram as contas anuais obrigatórias. A tal momento, o n. ${ }^{\circ} 1$ do art. $35^{\circ}$ acrescenta dois outros, que impõem também a actuação dos gerentes e administradores: quando as contas intercalares $^{33}$ da sociedade revelem que o capital próprio é igual ou inferior ao capital social, ou sempre que os gerentes e administradores tenham fundadas razões para admitir que essa perda se verifica.

Impõe-se, pois, que os gerentes e administradores actuem, imediata e prontamente, quer quando as contas revelem a perda de metade do capital social, quer sempre que tenham fundadas razões para admitir que essa perda se verifica. Assim sendo, impõe-se a qualquer gerente ou administrador criterioso e diligente uma ininterrupta atenção à evolução da situação patrimonial da sociedade.

\subsection{Obrigações a cargo dos gerentes e administradores}

Quem tem a obrigação de verificar, a todo o momento, se a sociedade perdeu metade do capital social são os gerentes e administradores, o que se compreende, pois a eles cabe a administração da sociedade.

Verificada a perda de metade do capital social, nos termos acima referidos, são os gerentes das sociedades por quotas obrigados a convocar a assembleia geral dos sócios, e os administradores das sociedades

\footnotetext{
${ }^{3 t}$ Em bom rigor o que se perdeu foi metade do capital próprio e não do capital social, como esclarece o n. ${ }^{\circ} 2$ do art. $35^{\circ}$.

${ }^{32}$ Importará, porém, que se trate de uma perda definitiva, isto é, irrecuperável a curto prazo, pois não faria sentido informar os sócios e convocar uma assembleia geral perante uma perda momentânea ou ocasional

${ }^{33}$ São contas elaboradas durante o exercicio, por determinação legal especial, por imposição estatutária ou decorrentes da prática de cada sociedade - cf. MENESES CORDEIRo, "A perda de metade do capital social e a reforma de 2005: um repto ao legislador", p. 80.
} 
anónimas obrigados a pedir ao presidente da mesa da assembleia geral a convocação da mesma.

Nos termos da lei, verificada a perda de metade do capital social, a convocação da assembleia deve ser imediata ${ }^{34}$. O objectivo da convocação dos sócios é informá-los da situação em que a sociedade se encontra. Isto é, estamos perante uma obrigação de informar que recai sobre os gerentes e administradores. Destaca-se, deste modo, a função preventiva que o artigo $35^{\circ}$ pretende desempenhar.

Caberá então aos sócios, assim informados, «tomarem as medidas julgadas convenientes», a fim de corrigir o desequilíbrio verificado. Para esse efeito, a ordem de trabalhos da assembleia a convocar deve incluir os assuntos constantes do ${ }^{\circ}{ }^{\circ} 3$ do artigo $35 .^{\circ}$, quais sejam:

- A dissolução da sociedade;

- A redução do capital social para montante não inferior ao capital próprio da sociedade;

- A realização pelos sócios de entradas para reforço da cobertura do capital.

Importa sublinhar que, de acordo com a última redacção do artigo $35 .^{\circ}$, os gerentes e administradores deixam de estar expressamente obrigados a mencionar a perda de metade do capital social no relatório de gestão, desaparecendo também a obrigação de proporem aos sócios a adopção de medidas tendentes a alterar tal situação. Cabe-lhes apenas convocar ou requerer a convocação da assembleia geral, na qual deverão informar os sócios da situação de perda de metade do capital social. Porém, atento o conteúdo que o relatório de gestão deve ter, é exigível que o mesmo a refira ${ }^{35}$.

Mantêm-se, contudo, as sanções para o incumprimento das obrigações que recaem sobre os gerentes e administradores. Assim, se os membros da administração não cumprirem as obrigações que o artigo $35 .^{\circ}$ Ihes impõe, sujeitam-se a sanções de natureza criminal, uma vez que o artigo $523 .^{\circ}$ do Código das Sociedades Comerciais - que apenas

\footnotetext{
${ }^{34} \mathrm{Na}$ redacção de original do art. $35 .^{\circ}$, as propostas a apresentar pela administração quando não o fossem na própria assembleia de aprovação das contas deveriam ser apresentadas em assembleia convocada para os 60 dias seguintes. Na redacção de 2002 este prazo passou para 90 dias. Agora não é estabelecido um prazo, diz-se apenas que os gerentes devem convocar de «imediato» a assembleia e os administradores requerer «prontamente» a sua convocação.

${ }^{35} \mathrm{Cf}$. art. $66{ }^{\circ}$ do CSC.
} 
foi alterado para eliminar a referência aos directores e efectuar alguns retoques na redacção - determina que:

«O gerente ou administrador de sociedade que, verificando pelas contas de exercício estar perdida metade do capital, não der cumprimento ao disposto nos $\mathrm{n}^{\circ}{ }^{\circ} \mathrm{s} 1$ e 2 do artigo $35 .^{\circ}$ é punido com prisão até 3 meses e multa até 90 dias» ${ }^{36}$.

Acresce que, para além da sanção penal, pode também haver responsabilidade civil pelos prejuízos que da sua conduta omissiva resultem para a sociedade ${ }^{37}$, para os credores sociais ${ }^{38}$, para os sócios ou para qualquer terceiro ${ }^{39}$.

Nas sociedades por quotas, serão os gerentes que, verificando a perda grave ou admitindo fundamentadamente que ela ocorre, deverão convocar de imediato os sócios para uma assembleia geral. A convocação pode ser efectuada por qualquer um dos gerentes ${ }^{40}$, pelo que basta que um deles se aperceba ou verifique a perda grave para que deva, de imediato, convocar todos os sócios para uma assembleia geral.

Acresce que, ainda que a perda seja do conhecimento de todos os sócios e todos eles sejam gerentes, a convocação da assembleia geral é necessária pois tal reunião não visa apenas informá-los dessa situação. Nos termos da lei, a assembleia é também convocada para que os sócios «tomem as medidas julgadas convenientes». Em alternativa à assembleia regularmente convocada pode ter lugar uma assembleia universal de sócios, desde que da ordem de trabalhos unanimemente aceite constem os assuntos previstos no $\mathrm{n}^{\circ} 3$ do art. $35 .^{\circ}$ do CSC.

Nas sociedades anónimas compete aos administradores requerer ao presidente da mesa a convocação da assembleia geral dos accionistas. É

\footnotetext{
${ }^{36}$ Esta norma já se aplicava à versão original do art. $35^{\circ}$. De resto, a referência ao n. ${ }^{\circ} 2$ do art. $35 .^{\circ}$ deixou de fazer sentido, na medida em que este número, na nova redacção, contém apenas uma definição, insusceptível, pela sua natureza, de ser violada. A referência agora deveria ser ao $n^{\circ} 3$ do mesmo artigo. Todavia, a nova redacção desta norma, introduzida pelo $\mathrm{DL} \mathrm{n}{ }^{\circ}{ }^{76-\mathrm{A} / 2004}$, manteve esta incorrecção. A este propósito, ver Menezes Cordeiro, "A perda de metade do capital social e a reforma de 2005: um repto ao legislador", p. 83, que advoga que perante "a vigente textura do art. $35 .^{\circ}$, esse preceito [art. $\left.523 .{ }^{\circ}\right]$ perdeu sentido útil".

${ }^{37} \mathrm{Cf}$. art. $72 .^{\circ}$, n. $^{\circ} 1$ do CSC.

${ }^{38} \mathrm{Cf}$. art. $78 .^{\circ}, \mathrm{n}^{\circ} 1$ do $\mathrm{CSC}$.

${ }^{39} \mathrm{Cf}$. art. $79 .^{\circ}, \mathrm{n}^{\circ} 1$ do CSC

${ }^{40} \mathrm{Cf}$. art. $248{ }^{\circ}$, n. $^{\circ} 3$ do CSC.
} 
ao presidente da mesa que cabe convocar a assembleia, pelo que os administradores mais não podem fazer do que solicitar-lhe que convoque os sócios, justificando tal pedido com a perda de metade do capital social. A convocatória da assembleia deve, ainda que de forma sumária, indicar o motivo da convocação e conter a ordem de trabalhos com os assuntos referidos no.$^{\circ} 3$ do art. $35 .^{\circ}$.

É certo que a competência para pedir a convocação da assembleia geral é do conselho de administração $0^{41}$, enquanto órgão colegial, pelo que este pode deliberar, por maioria ${ }^{42}$, pedir a convocação da assembleia ao presidente a mesa.

Porém, deve entender-se que qualquer administrador tem o dever de pedir ao presidente da mesa a convocação da assembleia geral sempre que uma das hipóteses previstas no n. ${ }^{\circ} 1$ do art. $35 .^{\circ}$ esteja verificada. Por um lado, é esse o sentido que resulta da referida norma, por outro, é o corolário da responsabilidade pessoal que sobre cada administrador recai, caso não observe tal dever ${ }^{43}$.

Refira-se que, se no âmbito do conselho de administração do modelo clássico for constituída uma comissão executiva, nenhuma razão existe para se pensar que apenas os administradores que a integrem estejam sujeitos ao dever de requerer a convocação da assembleia geral. De resto, a elaboração e apresentação das contas anuais é matéria que não é susceptível de delegação, como decorre do n. ${ }^{\circ} 4$ do art. $407 .^{\circ}$ do $\mathrm{CSC}^{44}$.

Na nova modalidade de estruturação das sociedades anónimas ${ }^{45}$, o chamado modelo anglo-saxónico, o conselho de administração compreende uma comissão de auditoria, da qual fazem parte administradores não executivos, e que funciona como órgão de fiscalização do próprio conselho de administração ${ }^{46}$. Neste modelo, apesar de os membros da

\footnotetext{
${ }^{41}$ Cf. art. $406 .^{\circ}$, c), aplicável ao conselho de administração executivo ex vi art. $431 .^{\circ}$, n. ${ }^{\circ} 3$, ambos do CSC.

${ }^{42} \mathrm{Cf}$. art. $410{ }^{\circ}, \mathrm{n} .^{\circ} 7$, aplicável ao conselho de administração executivo ex vi art. $433 .^{\circ}$, n. ${ }^{\circ}$. Se a sociedade tiver um administrador único, a este cabe exercer as competências do conselho - cf. art. $390{ }^{\circ}, \mathrm{n} .^{\circ} 2$ e art. $424 .^{\circ}, \mathrm{n}^{\circ}{ }^{\circ}$, todos do CSC.

${ }^{43} \mathrm{Cf}$. art. $523 .^{\circ}$ do CSC.

${ }^{44}$ Já no que respeita às contas intercalares, a sua competência pode ser delegada na comissão executiva.

${ }^{45}$ Prevista na alínea b), do $n .^{\circ} 1$, do art. $278 .^{\circ}$, do CSC.

${ }^{46} \mathrm{Cf}$. art. $423{ }^{\circ}-\mathrm{F}$, do CSC.
} 
comissão de auditoria terem as competências do conselho fiscal das sociedade de modelo latino, entendemos que também eles estão sujeitos à obrigação de requerer a convocação da assembleia geral, quando verifiquem estar perdida metade do capital social, pois também a eles são para todos os efeitos administradores, pelo que a eles se aplicam também os artigos $35 .^{\circ}$ e $523 .^{\circ}$, do CSC.

Em suma, qualquer administrador que, por qualquer forma, tome conhecimento da perda de metade do capital social ou tenha fundadas razões para admitir que tal situação se verifica, deve prontamente requerer ao presidente da mesa da assembleia geral a convocação de uma reunião geral de sócios, com a referida ordem de trabalhos, a fim de nela se informarem os sócios da ocorrência da perda grave.

\subsection{Publicidade da perda grave}

Inovação da reforma de 2005 é a obrigação de publicitar a situação de perda de metade do capital social. De facto, foi alterada a redacção do artigo $171 .^{\circ}$ do Código das Sociedades Comerciais que regula as menções obrigatórias nos actos externos. À enumeração já constante dos números 1 e 2 da referida norma foi aditada a obrigação de as sociedades por quotas, anónimas e em comandita por acções ${ }^{47}$ «indicarem o montante do capital próprio segundo o último balanço aprovado, sempre que este for igual ou inferior a metade do capital social».

Tal informação deve constar claramente em toda a sua actividade externa, nomeadamente, em todos os contratos, correspondência, publicações, anúncios e sítios na Internet.

A obrigação de publicitar a perda de metade do capital social só existe depois de ter sido aprovado o balanço que a revele e não quando esta apenas resulte de contas intercalares ou quando haja fundadas razões para admitir que ela se verifica. Esta exigência de publicitação manter-se-á enquanto não for aprovado outro balanço em que tal perda já não se verifique.

Pretende-se, com esta imposição de publicidade, salvaguardar os interesses de terceiros que contratem com a sociedade e que poderiam

\footnotetext{
${ }^{47}$ Desta obrigação foram excluídas as sucursais de sociedades com sede no estrangeiro, às quais apenas se aplica a exigência do $n .^{\circ} 1$ do art. $171 .^{\circ}-\mathrm{cf}^{\mathrm{n}} \mathrm{n} .^{\circ} 3$ do mesmo preceito.
} 
ser induzidos em erro pelo facto de a mesma ostentar um valor de capital social já sem correspondência com a sua efectiva situação patrimonial. De resto, a garantia geral do credor é o património da sociedade e este tem expressão no seu capital próprio (o mesmo é dizer, na sua situação líquida) e não no valor do capital social, como vimos.

Significa isto, em termos práticos, que se a nossa "ABC, Lda." permanecer em perda grave, nas facturas que emitir deverá ler-se uma indicação deste tipo: «o capital social é de $€ 30000,00$ e o capital próprio é de $€ 10000,00$ ».

Caso não dê cumprimento a esta obrigação de indicação do valor do capital próprio em todos os actos externos, a sociedade sujeita-se a uma coima, que pode ir de $€ 249,40$ a $€ 1496,39$, nos termos do n. ${ }^{\circ} 2$ do art. $528 .^{\circ}$ do CSC.

Importa, contudo, sublinhar que a obrigatoriedade de publicitação da perda grave cessa com o reequilíbrio das contas, comprovado por um balanço regularmente aprovado.

\subsection{Medidas a adoptar pelos sócios}

A) Soluções previstas no . $^{\circ} 3$ do art. $35 .^{\circ}$

$\mathrm{O}$ n. ${ }^{\circ} 3$ do art. $35 .^{\circ}$ enumera exemplificativamente algumas das medidas que os sócios poderão adoptar e que devem ser incluidas na ordem de trabalhos da convocatória a enviar aos sócios.

\section{- Dissolução da sociedade}

Perante a perda grave do capital social, os sócios, desde logo, podem optar por dissolver a sociedade ${ }^{48}$. Tratando-se de sociedades por quo$\operatorname{tas}^{49}$, para que tal proposta seja adoptada é necessário que seja aprovada por maioria de $3 / 4$ dos votos correspondentes ao capital social. Nas sociedades anónimas é necessário que a proposta de dissolução recolha dois terços dos votos emitidos, sendo certo que deve estar presente ou representado, em 1 a $^{\text {c }}$ convocatória, pelo menos $1 / 3$ do capital social. ${ }^{5051}$

${ }^{48}$ Trata-se de uma hipótese de dissolução por deliberação dos sócios, prevista no art. $\left.141 .^{\circ}, \mathrm{b}\right)$, do CSC.

${ }^{49} \mathrm{Cf}$. art. $265 .^{\circ}$ do CSC.

${ }^{50} \mathrm{Cf}$. artigos $383^{\circ}, \mathrm{n}^{\circ} 2$ e $386^{\circ}$, n. $^{\circ} 3$, do CSC.

${ }^{51}$ De acordo com a anterior redacção do n. ${ }^{\circ} 2$ do art. $141 .^{\circ}$ do CSC, a dissolução da sociedade era automática se durante dois exercícios consecutivos a perda grave se mantivesse, podendo os sócios deliberar o reconhecimento da dissolução por maioria 


\section{- Redução do capital social}

Uma solução que os sócios podem adoptar para assegurar a cobertura do capital social pelo capital próprio é a redução do capital social. Trata-se, nesta situação, de uma redução nominal, para cobertura de prejuízos, pelo que estamos perante uma operação formal de alteração da cifra do capital social, de forma a aproximá-lo do valor do capital próprio $^{52}$. Esta redução pode ser mesmo para valor inferior ao capital social mínimo, desde que condicionado à efectivação de um aumento nos 60 dias seguintes ${ }^{53}$.

A redução para compensar prejuízos consiste numa operação meramente formal, pelo que não ocorre nenhuma alteração patrimonial na sociedade $^{54}$, pelo que não carece de autorização judicial ${ }^{55}$. A vantagem que tem é a de adequar o capital social ao real valor da sociedade.

Como é uma alteração ao pacto social, esta redução do capital exige as mesmas maiorias que a dissolução da sociedade e tem que ser levada a registo na competente conservatória.

\section{- Realização de «entradas»}

Entre as soluções exemplificativamente previstas no $\mathrm{n}^{\circ} 3$ do art. $35 .^{\circ}$ do CSC conta-se ainda a «realização pelos sócios de entradas para reforço da cobertura do capital».

Em rigor, não estamos perante a realização de entradas, pois se assim fosse alterar-se-ia o capital social e estaríamos perante um aumento do capital social. Trata-se efectivamente da reposição das entradas perdidas, isto é, de uma contribuição realizada pelos sócios, em dinheiro ou em espécie, a fundo perdido, que não alterando o capital social aumenta o capital próprio da sociedade e portanto, reforça a cobertura do

simples, ou, qualquer sócio, sucessor de sócio, credor da sociedade ou credor de sócio de responsabilidade ilimitada, promover a justificação notarial da dissolução.

${ }^{52} \mathrm{~A}$ lei não permite a redução para valor inferior ao capital próprio. É que nesse caso estaríamos face a uma redução real, que permitiria a distribuição de bens aos sócios, a qual carece de autorização judicial (art. $95 .^{\circ}, \mathrm{n} .^{\circ} 1$, do CSC), pois pode pôr em causa o interesse dos credores.

${ }^{33} \mathrm{Cf}$. art. $96{ }^{\circ}$, n. $^{\circ} 1$, do CSC.

${ }^{54}$ Pode até facilitar a diminuição do capital próprio no futuro, pois após a redução do capital, baixando a cifra de retenção, torna-se mais fácil distribuir eventuais lucros. Exactamente por causa disso, o art. $96 .^{\circ}$, n. $^{\circ} 4$, alíneas c) e d), do CSC, permite que qualquer credor requeira ao tribunal a proibição de distribuição de reservas e de lucros, durante periodo a fixar.

${ }^{55} \mathrm{Cf}$. art. $95{ }^{\circ}$, n. $^{\circ} 3$, do CSC. 
capital social.

É uma solução simples, pois não implica alterar o pacto social, e que pode ser concretizada de imediato. Porém, tem um carácter necessariamente voluntário, isto é, só os sócios que livremente as queiram realizar a tal ficam obrigados, uma vez que não pode ser exigido aos sócios das sociedades de responsabilidade limitada que cubram os prejuízos da sociedade. E a nenhum sócio pode ser imposta a realização de entradas não previstas no pacto social.

Assim, caso não sejam deliberadas por unanimidade, estas entradas não são uma solução interessante, pois se apenas alguns sócios as efectuarem significará que há sócios que vão realizar entradas para viabilizar a sociedade sem qualquer contrapartida por tal facto. É uma solução simples e rápida, mas que só fará sentido se todos os sócios a decidirem adoptar.

\section{B) Outras soluções possíveis}

\section{- Aumento do capital social}

O aumento do capital social podendo constituir uma solução, não será na maioria das situações uma boa solução. Por um lado, implica uma alteração do pacto social, o que exige as mesmas maiorias que vimos serem necessárias no caso de dissolução da sociedade ou de redução do capital social. Por outro lado, não anula a diferença entre o capital próprio e o capital social, pois a um aumento do capital próprio, em virtude das entradas acordadas, corresponde igual incremento do capital social, pelo que o desequilíbrio persiste, apesar de atenuado.

Fará, porventura, mais sentido aumentar o capital social se esta medida for associada à sua redução para sanear prejuízos, naquilo que usualmente se denomina «operação acordeão».

\section{- Prestações suplementares}

Uma outra solução a que os sócios podem recorrer é a da realização de prestações suplementares de capital. Na verdade, estas prestações são contabilizadas como capital próprio ${ }^{56}$, atento o regime a que estão sujeitas $^{57}$, e constituem entradas que não contam para o capital social, pelo que são um instrumento adequado para resolver o problema do de-

\footnotetext{
${ }^{56}$ Ao contrário do que sucede com os suprimentos - cf. POC, conta 53 «Prestações suplementares», do Activo, e conta 25 «Accionistas (sócios)», do Passivo.

${ }^{57}$ Artigos $210 .^{\circ}$ a $213 .^{\circ}$, do CSC.
} 
sequilíbrio entre o capital próprio e o capital social. Além disso, têm a vantagem de ser possível a sua devolução aos sócios que as efectuaram, se a situação da sociedade no futuro o vier a permitir, ao contrário do que sucede com a reposição das entradas de que falámos atrás. Torna-se, assim, uma solução mais aceitável para aquelas sociedades em que nem todos os sócios irão realizar estas entradas suplementares.

Se o contrato de sociedade não previr a possibilidade de ser deliberada a realização de prestações suplementares - previsão que só será possível nas sociedades por quotas - tal não impede que os sócios ou alguns deles possam fazer voluntariamente contribuições sujeitas ao seu regime.

$\mathrm{O}$ mesmo se diga quanto às prestações suplementares nas sociedades anónimas. Sendo discutivel se o contrato de sociedade as pode prever ou não, certo é que não existe nenhum obstáculo a que os sócios que o desejem possam fazer contribuições em dinheiro, sujeitas ao regime das prestações suplementares.

\section{- Apresentação à insolvência}

A perda grave do capital social pode também configurar uma situação de insolvência. Uma sociedade comercial considera-se insolvente quando se encontra impossibilitada de cumprir as obrigações vencidas ou quando se verifique uma manifesta superioridade do passivo sobre o activo ${ }^{58}$. Perante tal situação, podem os sócios deliberar a apresentação da sociedade à insolvência, cabendo aos gerentes e administradores dar execução prática a tal deliberação. De resto, sãos os órgãos de administração têm legitimidade activa para requerer a declaração de insolvência $^{59}$, estando mesmo a tanto obrigados, a partir do conhecimento da situação de insolvência ${ }^{60}$.

\section{- Reavaliação do activo}

Importa, por último, referir uma outra forma de resolver o problema regulado no art. $35 .^{\circ}$ e que passa pelo aumento do capital próprio por via da reavaliação do activo. É sabido que, de acordo com as regras da contabilidade, os elementos do activo são inscritos pelos seus va-

\footnotetext{
${ }^{58} \mathrm{Cf}$, art. ${ }^{\circ} 3{ }^{\circ}$ do Código da Insolvência e da Recuperação de Empresas (CIRE).

${ }^{59} \mathrm{Cf}$. art. $19 .{ }^{\circ}$, conjugado com o ${ }^{\circ} .^{\circ} 1$ do art. $6 .^{\circ}$, ambos do CIRE.

${ }^{60}$ Nos termos do art. 18. ${ }^{\circ}$ do CIRE, a apresentação à insolvência deve ser efectuada nos 60 dias seguintes à data do conhecimento da situação de insolvência, sob pena de sanções civis (artigos $186 .^{\circ}$ e $189 .^{\circ}$, do CIRE) e criminais (artigos 228. ${ }^{\circ}$, n. ${ }^{\circ} 1$ e $2290^{\circ}-$ A, do Código Penal).
} 
lores históricos de aquisição. Porém, fruto da depreciação monetária, tais bens podem figurar por valores muito depreciados, pelo que se pode justificar a sua reavaliação, a fim de incorporar nas contas da sociedade o efeito da inflação.

Ora, efectuada a reavaliação, o seu saldo (positivo) tem que ser levado a reserva, como impõe a alínea b), do n. ${ }^{\circ} 2$ do art. $295 .^{\circ}$, do $\mathrm{CSC}^{61}$, sujeita ao regime da reserva legal. Poderá pois ser usada para compensar prejuízos ou para incorporação no capital social. Certo é que, o saldo da reavaliação, aumentando a conta de reservas, aumentam o capital próprio, pelo que podem, por si só, repor o equilíbrio entre este e o capital social.

\section{CRISE DO CAPITAL SOCIAL}

A função principal do capital social - a função rainha, como se disse - é a de garantia perante os credores sociais, função essencial, atenta a irresponsabilidade dos sócios por dívidas socais que vigora nas sociedades de responsabilidade limitada.

Todavia, o capital social desempenha esta função de forma muito limitada. Já sabemos que ele constitui apenas uma garantia indirecta, ou seja, que por si mesmo nada garante. Todavia, pretende assegurar a existência do chamado "capital social real», isto é, de uma massa de bens que cubra o valor da cifra constante do pacto. Mesmo neste âmbito, a sua eficácia é muito limitada pois a cobertura do capital social não assegura a existência de liquidez para solver os compromissos assumidos perante terceiros. É que pode não se colocar nenhum problema de cobertura do capital social mas o património não possuir a liquidez que assegure o pagamento das dívidas aos credores.

Bem vistas as coisas, o que o capital social garante, como cifra de retenção, é que o património não desaparece por força de distribuição aos sócios. Na verdade, ele impede o retorno aos sócios do valor das entradas por estes efectuadas, caso o capital social não esteja coberto. $\mathrm{O}$ que significa que mesmo uma sociedade com um capital social muito elevado pode ter um património líquido nulo, pois aquele não garante a

\footnotetext{
${ }^{61}$ Esta obrigatoriedade de levar estes saldos a reservas decorre também do art. $33 .^{\circ}$, n. ${ }^{\circ} 2$, a), da Quarta Directiva (Directiva n. ${ }^{\circ} 78 / 660 / \mathrm{CEE}$, do Conselho, de 25 de Julho de 1978, JOCE n. ${ }^{\circ}$ L-222, de 14/08/1978).
} 
existência do capital próprio de valor semelhante. E perante uma perda grave do capital social, como vimos, apenas existe a obrigação de a administração convocar os sócios para os informar da situação com que a sociedade se defronta e de se lhe dar publicidade nos actos externos.

Mesmo enquanto cifra de retenção não pode deixar de se constatar a forma limitada como desempenha esta sua função. Desde logo, pelo facto de se tratar de um valor nominal, o qual não está sujeito a qualquer alteração decorrente da desvalorização monetária, o que significa em termos reais, que com o passar dos anos, o capital social baixa, reduzindo os níveis de retenção. A tal facto acresce ainda que, na maioria das sociedades, o capital social inicial é, logo à partida, muito inferior ao valor de capital próprio de que a sociedade carece, sendo usual que os sócios estipulem o valor mínimo que a lei exige, provocando um fenómeno de subcapitalização.

Refira-se ainda que o funcionamento do capital social não se adequa ao regime das sociedades em grupo, podendo gerar o denominado "efeito telescópio" 62 , acabando por pouco garantir aos credores. $\mathrm{Na}$ verdade as regras relativas à conservação do capital social não têm como referência o balanço consolidado do grupo, nem o seu capital social consolidado.

Imagine-se, por exemplo, que os nossos António, Bento e Carla, deliberam constituir uma nova sociedade, cujo capital social de $€ 15000,00$ vai ser subscrito em dinheiro pela "ABC, Lda.". Neste caso, o capital social consolidado será de $€ 45000,00$ ( $€ 30000,00+$ $€ 15000,00)$, sendo certo que o património líquido consolidado não será mais que $€ 30000,00$.

Estas são algumas das insuficiências pelas quais tem sido posto em causa, nos últimos anos na Europa, o papel do capital social no regime jurídico-societário. Para além de não cumprir cabalmente o que dele a economia exigiria, é acusado de poder ainda constituir um entrave ao desenvolvimento económico, com a exigência de capitais sociais mínimos que podem ser desencorajadores para quem quer iniciar-se no exercício do comércio. Ora, não é possível abolir a exigência de um capital social mínimo e querer, simultaneamente, assegurar o princípio de que o capital social é uma garantia para os credores.

${ }^{62}$ Para usar a expressão de Fernandez del Pozo, em "Aplicación de resultados y defensa del capital social", p. 8564. 
Contudo, cada vez mais se vai impondo a ideia de acabar com o capital social mínimo para a constituição de sociedades. Esta ideia tem vindo a ganha adeptos, sobretudo no que respeita às sociedades de responsabilidade limitada, às quais não se aplica a exigência do capital social mínimo imposto pela Segunda Directiva às sociedades anóni$\operatorname{mas}^{63}$.

Acresce que, a jurisprudência do Tribunal de Justiça das Comunidades Europeias, por mais de uma vez ${ }^{64}$, decidiu que «o facto de um nacional de um Estado-membro, que pretenda criar uma sociedade, optar por constitui-la no Estado-membro cujas normas de direito das sociedades lhe pareçam menos rigorosas e criar seguidamente sucursais noutros Estados-membros é inerente ao exercicio, num mercado único, da liberdade de estabelecimento garantida pelo Tratado». ${ }^{65}$

Encontra-se, assim, criado um mercado único de regimes jurídico-societários ${ }^{66}$, no qual estão à partida em piores condições para atrair a constituição de sociedades comerciais aqueles que maiores exigências coloquem, nomeadamente no que concerne ao montante do capital social mínimo exigido e às regras da sua realização.

Importa, pois, acompanhar este repensar do direito societário,

\footnotetext{
${ }^{63}$ Em França, a Lei n. ${ }^{\circ} 2003-721$, de 1 de Agosto de 2003, chamada "Loi pour l'initiative économique" (LIE), revogou a exigência de um capital social mínimo para as sociedades de responsabilidade limitada (SARL). Já não era exigido capital social mínimo para as sociedades por quotas nos Estados Unidos, no Reino Unido e no Canadá - cf. Alexandre Mota Pinto, Capital social e tutela dos credores, p. 17.

${ }^{64}$ Cf. os acórdãos do Tribunal de Justiça das Comunidades Europeias de 9 de Março de 1999 (Proc. N. ${ }^{\circ}$ C-212/97 - "Centros Ltd contra Erhvervs - og Selskabsstyrelsen", disponível em «http:/eur-lex.europa.eu/LexUriServ/LexUriServ.do?uri=CELEX:61997J0212:PT: HTML») e de 30 de Setembro de 2003 (Proc. N. ${ }^{\circ}$ C-167/01 - "Kamer van Koophandel en Fabrieken voor Amsterdam c/ Inspire Art Ltd", disponível em «http://eur-lex.europa. eu/LexUriServ/LexUriServ.do?uri=CELEX:62001J0167:PT:HTML»).

${ }^{65} \mathrm{Cf}$. o referido Acórdão do Tribunal de Justiça das Comunidades Europeias de 30 de Setembro de 2003 "Inspire Ltd", n. ${ }^{\circ} 138$.

${ }^{66} \mathrm{Cf}$. Alexandre Mota Pinto, Capital social e tutela dos credores, p. 17. A ideia de que é incompatível com a liberdade de estabelecimento que a uma sociedade constituída num Estado-membro ao abrigo do direito ai vigente não seja reconhecida capacidade jurídica num outro Estado-membro para o qual este considera transferida a sede efectiva foi consagrada no importante acórdão do Tribunal de Justiça das Comunidades Europeias de 5 de Novembro de 2002 (Proc. N. ${ }^{\circ}$ C-280/00 - "Überseering BV contra Nordic Construction Company Baumanagement GmbH (NCC)”, disponível em «http:/ eur-lex.europa.eu/LexUriServ/LexUriServ.do?uri=CELEX:62000J0208:PT:HTML»).
} 
aberto pela Comissão na sua Comunicação de $21.05 .2003^{67}$, e à luz dos últimos desenvolvimentos jurisprudenciais do Tribunal de Justiça das Comunidades Europeias, tendo presente que está prevista a introdução na Segunda Directiva de um regime alternativo ao capital social, o que é apontado para depois de 2009.

Qualquer que seja o regime que venha a ser adoptado, não pode deixar de ter em devida conta a necessidade de assegurar a confiança dos credores, limitando a distribuição de bens aos sócios e assegurando mínimos de solvabilidade, independentemente dos critérios que possam ser estabelecidos ${ }^{68}$.

Em síntese final, importa reter três ideias essenciais:

Que a plena compreensão do regime da perda grave impõe o diálogo entre o Direito Comercial e a Contabilidade;

Que, bem vistas as coisas, não é grave ter uma "perda grave" (do capital social);

Que urge acompanhar com atenção o repensar do capital social a que se assiste na União Europeia.

\footnotetext{
${ }^{67}$ Cf. supra, nota 2.

${ }^{68}$ Cf. Relatório WinTER que propõe trocar o capital social por dois testes de solvabilidade: $1^{\circ}$ - $\mathrm{O}$ activo depois da distribuição tem que ser superior ao passivo (com exclusão do valor das acções); $2^{\circ}$ - Existência de liquidez para assegurar o pagamento de todas as dívidas à medida que elas se forem vencendo.
} 


\section{BIBLIOGRAFIA}

ABREU, Jorge Manuel Coutinho de - Curso de Direito Comercial. Vol. II. Coimbra: Almedina, 2002.

BROSETA PONT, Manuel / MARTÍNEZ SANZ, Fernando - Manual de Derecho Mercantil - Vol. I. 11 1 a ed. Madrid: Tecnos, 2002.

CONAC, Pierre-Henri - Le capital dans le droit américain des sociétés, Quel avenir pour le capital social?. Paris: Dalloz, 2004. p. 153.

CORDEIRO, António Menezes - A perda de metade do capital social e a reforma de 2005: Um repto ao legislador. Revista da Ordem dos Advogados. Ano 65, tomo 1 (Junho 2005) p. 45.

CORDEIRO, António Menezes - Da Perda de Metade do Capital Social das Sociedades Comerciais. Revista da Ordem dos Advogados. Ano 56, vol. I (1996) p. 157.

CORREIA, A. Ferrer - Lições de Direito Comercial. Vol. II. Sociedades Comerciais - Doutrina geral. Coimbra: edição policopiada, 1968.

CORREIA, Miguel J. A. Pupo - Direito Comercial - Direito das Empresas. 9 $^{\text {a }}$ ed. Lisboa: Ediforum, 2005.

DOMINGUES, Paulo de Tarso - A perda grave do capital social. Separata de Estudos em Homenagem ao Professor Doutor Jorge Ribeiro de Faria. Coimbra: Coimbra Editora, 2003.

DOMINGUES, Paulo de Tarso - Do Capital Social - Noção, Principios e Funções. 2. ${ }^{a}$ ed. Coimbra: BFDUC / Coimbra Editora, 2004.

FERNÁNDEZ DEL POZO, Luis - Aplicación de resultados y defensa del capital social. De nuevo sobre la crisis (presunta) de la noción de capital social. Revista General de Derecho. N. ${ }^{\circ} 622-623$ (1996) p. 8543 .

FURTADO, Jorge Henrique Pinto - Curso de Direito das Sociedades. $5^{\mathrm{a}}$ ed. Coimbra: Almedina, 2004.

MACHADO PLAZAS, José - Perdida del capital social y responsabilidad de los administradores por las deudas sociales. Madrid: Civitas, 1997.

PINTO, Alexandre Mota - Capital social e tutela dos credores - Para acabar de vez com o capital social mínimo nas sociedades por quotas. Texto da comunicação apresentada no Congresso Empresas e 
Sociedades, Março, 2006, Auditório da Faculdade de Direito da Universidade de Coimbra (texto policopiado).

PINTO, Alexandre Mota - O artigo $35 .^{\circ}$ do Código das Sociedades Comerciais na versão mais recente. Coimbra: Temas Societários/ IDET/ Almedina, 2006. p. 107.

SANTOS, Filipe Cassiano dos - A Posição do Accionista Face aos Lucros de Balanço. Coimbra: BFDUC/ Coimbra Editora, 1996. 